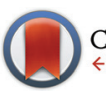

CrossMark \& click for updates

Cite this: Polym. Chem., 2016, 7, 1659

Received 4th December 2015 Accepted 22nd January 2016 DOI: $10.1039 / c 5 p y 01934 f$ www.rsc.org/polymers

\title{
A well-defined block copolymer synthesis via living cationic polymerization and nitroxide- mediated polymerization using carboxylic acid-based alkoxyamines as a dual initiator $\dagger$
}

\author{
Dao Le, Trang N. T. Phan, * Laurent Autissier, Laurence Charles and Didier Gigmes
}

A series of carboxylic acid-based alkoxyamines associated with $\mathrm{SnBr}_{4}$, a Lewis acid, have been used as protonic acids of a binary initiating system to control the cationic polymerization of vinyl ether. The living character of the homopolymerization of isobutyl vinyl ether was investigated under various conditions (solvent, amount of catalyst, initiator structure etc.). Among the different studied dual initiators, TEMPO based-alkoxyamine showed high efficiency to lead the polymerization of isobutyl vinyl ether (IBVE) in a controlled manner. The prepared polymers exhibited high TEMPO functionality $(>0.85)$ and low dispersity (1.2) which is essential for the synthesis of well-defined block copolymers thereafter. TEMPO-functionalized PIBVE was used as a macro-initiator controller in the nitroxide-mediated polymerization (NMP) of styrene at $130{ }^{\circ} \mathrm{C}$ leading successfully to well-defined block copolymers of poly(isobutyl vinyl ether)- $b$ polystyrene (PIBVE-b-PS) with a narrow dispersity (1.2).

\section{Introduction}

Due to their applications in a wide range of domains such as surface modifiers, compatibilizers, coating materials, antistatic agents, adhesives, drug delivery and information storage systems, block copolymers have always been attracting researchers' interest. ${ }^{1,2}$ Usually, block copolymers are prepared by the coupling reaction of homopolymers, sequential addition of monomers in a living polymerization system, chain-end transformation approach or using a dual initiator. $^{2-4}$ Among them, dual initiator systems show many advantages compared to other approaches because they provide the opportunity to combine mechanistically incompatible monomer units into the same macromolecule. ${ }^{4}$ Basically, a dual initiator is a component, which contains two different initiation functions, which are selective for a different polymerization mechanism. The use of such an initiator requires however that each initiating group remains stable in both types of polymerization conditions. ${ }^{5}$

Following the discovery of a hydrogen iodide/iodine initiating system by Higashimura and Sawamoto, ${ }^{6}$ a variety of binary initiating systems consisting of protonic acid/Lewis acid were

Aix-Marseille Université, CNRS, Institut de Chimie Radicalaire UMR 7273, 13397 Marseille, France.E-mail: trang.phan@univ-amu.fr

$\dagger$ Electronic supplementary information (ESI) available: The ${ }^{1} \mathrm{H}$, and ${ }^{13} \mathrm{C}$ spectra of A2 and A3 alkoxyamines, SEC chromatograms and MS spectra of PIBVEmacroalkoxyamine. See DOI: 10.1039/c5py01934f developed to polymerize vinyl ether monomers in a living/controlled manner. ${ }^{7-13}$ Hence, various functional block copolymers composed of vinyl ether monomer units were synthesized acting as polymer surfactants, ${ }^{14,15}$ antibacterial agents, ${ }^{16-21}$ glycopolymer stimuli-responsive micelles and gels, ${ }^{16,18-21}$ thermoplastic elastomers, ${ }^{22,23}$ or optical plastics. ${ }^{24}$ By combination those binary initiating systems with living/ controlled radical polymerization techniques such as reversible addition-fragmentation transfer polymerization (RAFT) or atom transfer radical polymerization (ATRP), block-, statisticaland graft copolymers of vinyl ether monomers with radically polymerizable monomers have been subsequently achieved using the chain-end chemical transformation strategy or the use of a dual initiator. ${ }^{25-38}$ Sugihara et al. ${ }^{31,32}$ used mono- and dicarboxylic RAFT agents for the synthesis of $\mathrm{AB}$ and $\mathrm{ABA}$ block copolymers by the transformation of living cationic polymerization (LCP) into RAFT polymerization. In such a process, the LCP was initiated from the proton generated by a carboxylic RAFT agent to form a poly(vinyl ether)-bearing RAFT group as a counteranion. The latter was then used in the RAFT process for the synthesis of the second block. On the other hand, Kamigaito et al. ${ }^{34,35,38}$ demonstrated that the thioester bond of a RAFT agent can be activated by Lewis or Brønsted acid to mediate the LCP of a vinyl ether monomer. The ability of generating cationic and radical intermediates of the RAFT agent allows the synthesis of diblock- or multiblock copolymers of vinyl ether and meth(acrylate) or vinyl acetate monomers by subsequent or simultaneous LCP and RAFT 
polymerization. Du Prez et $a l^{36}{ }^{36}$ reported the synthesis of a dual initiator containing $\mathrm{Br}$ and acetal end groups that can be used both sides to prepare $\mathrm{AB}$ and $\mathrm{ABC}$ block copolymers by ATRP and LCP. As far as we are aware, the combination of protonic acid/Lewis acids/additive-base initiation system and nitroxide-mediated polymerization (NMP) using a multi-functional initiator for the synthesis of block copolymers has not been reported yet. NMP is historically the first and perhaps the easiest controlled/living radical polymerization method to apply. It allows the polymerization, in a controlled manner, a large range of monomers both in homogeneous and heterogeneous media and the synthesis of block copolymers and complex architectures. ${ }^{39}$

The desire to learn more about the feasibility of the NMP process in combination with a cationic polymerization system, we studied, in this work, the synthesis of poly(vinyl ether)based block copolymers with a radically polymerizable monomer having a well-defined structure and controlled molecular weight. The synthesis was achieved by LCP and subsequent NMP using carboxylic-based alkoxyamines as a dual initiator, as shown in Scheme 1. It is well-known that due to its relatively low acidity, the carboxylic acid can be part of initiators ${ }^{40,41}$ or chain transfer agents ${ }^{42}$ without affecting the CRP process. This functionality could be useful for the post chemical modification of the produced polymers. Moreover, carboxylic acids are one of the most versatile protonic acids that have been employed as the initiating systems for vinyl ether LCP.,10,13,37,43 Besides the acidity of carboxylic and Lewis acids, the steric crowding of the carboxylate counteranion is also an important factor to control the cationic polymerization. It has been reported that it influences the dynamic equilibrium between active and dormant species, hence, the polymerization behavior. For instance, Hashimoto et $a .^{11-13}$ studied the steric effects of the counteranion on the cationic polymerization of isobutyl vinyl ether using a series of carboxylic acids $(\mathrm{RCOOH})$ with $\mathrm{R}=\mathrm{CH}_{3} \mathrm{CH}_{2},\left(\mathrm{CH}_{3}\right)_{2} \mathrm{CH}$, $\left(\mathrm{CH}_{3}\right)_{3} \mathrm{C}, \mathrm{C}_{6} \mathrm{H}_{5} \mathrm{CH}_{2}$, etc. They found that all studied carboxylic acids gave living polymers but the steric hindrance of carboxylate counteranions significantly affected the polymerization rate and broadened the molecular weight distributions of the produced polymers. In order to obtain well-defined block copolymers, in this work, we have also studied the influence of

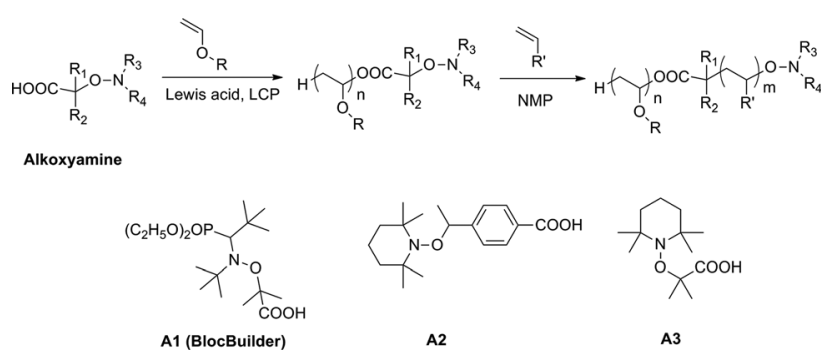

Scheme 1 Combination of living cationic polymerization and nitroxidemediated polymerization using carboxylic-based alkoxyamine and structure of alkoxyamines used in this study. the initiator structure on the living/controlled characters of LCP. To get a better insight on how the structure of a bifunctional initiator could affect the living/controlled characters of cationic polymerization, a series of carboxylic acid-based alkoxyamines were prepared and used as initiators of LCP and NMP (Scheme 1). Among them, the alkoxyamine BlocBuilder ${ }^{40}$ (A1) which enables to control the polymerization of a wide range of monomers such as styrene, acrylate and acrylamide by NMP. ${ }^{39,44,45}$ However, considering the steric crowding of the carboxylic group of $\mathbf{A 1}$, the use of the latter as the initiator in cationic polymerization of vinyl ether could significantly influence the polymerization in terms of reaction kinetics and broadening of the polymer molecular weight distributions. Moreover, the presence of a diethyl phosphate group in $\mathbf{A 1}$ may interact as a Lewis base with Lewis acid, thereby decreasing the living/controlled characters. ${ }^{10}$ Another series of initiators consisting of TEMPO-based alkoxyamines have been also considered. Typically, the alkoxyamines A2 and A3 bearing a benzoic acid derivative and a methyl-propanoic acid respectively have been prepared and investigated.

\section{Experimental section}

\section{Materials}

Isobutyl vinyl ether (IBVE) (Sigma-Aldrich; 99\%) was washed with water and distilled over calcium hydride and stored under nitrogen at $-20{ }^{\circ} \mathrm{C}$. Anhydrous toluene (>99.8\%), anhydrous dioxane $(>99.8 \%)$, anhydrous tetrahydrofuran (THF, >99.8\%), $\mathrm{SnBr}_{4}$ (99\%), 2,2,6,6-tetramethylpiperidine 1-oxyl (TEMPO, 98\%), 2-bromo-2-methylpropionic acid (98\%), 4-(1-bromoethyl)benzoic acid (97\%), $N, N, N^{\prime}, N^{\prime \prime}, N^{\prime \prime}$-pentamethyldiethylenetriamine (PMDETA, 99\%) and other compounds were purchased from Sigma-Aldrich and used without further purification. BlocBuilder® (>99\%), an alkoxyamine based on the nitroxide SG1 ( $N$-tert-butyl- $N$-[1-diethylphosphono-(2,2-dimethylpropyl)]nitroxide) was kindly provided by Arkema (France). All solvents and other reagents were purchased from commercial sources and used as received. Salts (lithium chloride, sodium chloride, ammonium acetate) used as cationizing agents in ESI-MS experiments were purchased from SigmaAldrich.

\section{Characterization techniques}

${ }^{1} \mathrm{H}$ and ${ }^{31} \mathrm{P}$ NMR spectra in $\mathrm{CDCl}_{3}$ were recorded on a Bruker Advance 400 spectrometer. Chemical shifts are given in ppm relative to tetramethylsilane in the case of ${ }^{1} \mathrm{H}$ NMR spectra.

Polymer molecular weights and dispersities were determined by size exclusion chromatography (SEC). The used system was an EcoSEC (Tosoh, Japan) equipped with a PL Resipore Precolumn $(4.6 \times 50 \mathrm{~mm}$, Agilent $)$ and two linear $\mathrm{M}$ columns $(4.6 \times 250 \mathrm{~mm}$, Agilent $)$ with a gel particle diameter of $3 \mu \mathrm{m}$. These columns were thermo-stated at $40{ }^{\circ} \mathrm{C}$. Detection was made by using an UV/visible detector operated at $\lambda=$ $254 \mathrm{~nm}$ and a dual flow differential refractive index detector, both from Tosoh, and a viscometer ETA2010 from PSS. 
Measurements were performed in THF at a flow rate of $0.3 \mathrm{~mL}$ $\mathrm{min}^{-1}$. Calibration was based on polystyrene standards from Polymer Laboratories (ranging from $370 \mathrm{~g} \mathrm{~mol}^{-1}$ to $371100 \mathrm{~g} \mathrm{~mol}^{-1}$ ).

High-resolution MS mass spectrometry (HR-MS) and MS/ MS experiments were performed using a QStar Elite mass spectrometer (AB SCIEX, Concord, ON, Canada) equipped with an electrospray ionization source operated in the positive mode. The capillary voltage was set at $+5500 \mathrm{~V}$ and the cone voltage at $+75 \mathrm{~V}$. In this hybrid instrument, ions were measured using an orthogonal acceleration time-of-flight (oaTOF) mass analyzer. A quadrupole was used for selection of precursor ions to be further subjected to collision-induced dissociation (CID) in MS/MS experiments. In the MS mode, accurate mass measurements were performed using reference ions from a poly(ethylene glycol) internal standard. The precursor ion was used as the reference for accurate measurements of product ions in the MS/MS mode. In this instrument, air was used as the nebulizing gas (10 psi) while nitrogen was used as the curtain gas (20 psi) as well as the collision gas. Instrument control, data acquisition and data processing of all experiments were achieved using Analyst software (QS 2.0) provided by AB Sciex. Sample solutions were prepared in methanol supplemented with $\mathrm{LiCl}(1.0 \mathrm{mM}), \mathrm{NaCl}(1.0 \mathrm{mM})$ or ammonium acetate $(3.0 \mathrm{mM})$ and were introduced in the ionization source using a syringe pump at a $5 \mu \mathrm{L} \mathrm{m^{-1 }}$ flow rate.

\section{Alkoxyamine synthesis}

TEMPO (1 g, $6.4 \mathrm{mmol}), 2$-bromo-2-methylpropionic acid or 4-(1-bromoethyl)benzoic acid (1.2 eq.), $\mathrm{Cu}$ (1.2 eq.), $\mathrm{CuBr}$ (1.2 eq.), THF (30 mL) and a stir bar were added into a twoneck round flask. The flask was sealed with a rubber septum and purged with argon for 20 minutes. Degassed PMDETA (2.4 eq.) was added into the glass flask using dry medical syringes. The resulting solution was subsequently stirred at room temperature for $24 \mathrm{~h}$. The reaction mixture was diluted with dichloromethane (DCM) $(100 \mathrm{~mL})$ and then washed with $3 \times$ $100 \mathrm{~mL}$ of an aqueous disodium ethylenediamine-tetraacetate solution to remove the catalyst. The organic layer was dried over $\mathrm{MgSO}_{4}$, filtered, and evaporated. The alkoxyamines were then purified by chromatography on a silica gel column using a mixture of DCM/ethyl acetate $(2 / 1 \mathrm{v} / \mathrm{v})$ as the eluent.

\section{4-(1-((2,2,6,6-Tetramethylpiperidin-1-yl)oxy)ethyl)benzoic acid, $\mathbf{A} 2$}

White powder, yield: $40 \%$.

${ }^{1} \mathrm{H} \mathrm{NMR}\left(400 \mathrm{MHz}, \mathrm{CDCl}_{3}\right): \delta(\mathrm{ppm})=8.00(\mathrm{~d}, J=8.3 \mathrm{~Hz}$, $2 \mathrm{H}, \operatorname{Ar} H), 7.35(\mathrm{~d}, J=8.2 \mathrm{~Hz}, 2 \mathrm{H}, \operatorname{Ar} H), 4.79(\mathrm{~d}, J=6.7 \mathrm{~Hz}, 1 \mathrm{H}$, $\mathrm{CH}_{3} \mathrm{CH}$ ), 1.42 (d, $\left.J=6.7 \mathrm{~Hz}, 3 \mathrm{H}, \mathrm{CH}_{3} \mathrm{CH}\right), 1.31-0.57(\mathrm{~m}, 18 \mathrm{H}$, $\mathrm{CH}_{3}-\mathrm{C}, \mathrm{CH}_{2}-\mathrm{CH}_{2}-\mathrm{CH}_{2}$ ), (Fig. S1†).

${ }^{13} \mathrm{C} \mathrm{NMR}\left(\mathrm{CDCl}_{3}\right): \delta(\mathrm{ppm})=171.46,152.12,130.18,127.71$, 126.59, 83.00, 59.78, 40.32, 34.18, 23.59, 20.33, 17.17, (Fig. S2†).

ESI-HRMS. Calc. for $\left[\mathrm{C}_{18} \mathrm{H}_{27} \mathrm{NO}_{3}+\mathrm{H}\right]^{+}: \mathrm{m} / \mathrm{z}$ 306.2064, found: $m / z 306.2068$.
2-Methyl-2-((2,2,6,6-tetramethylpiperidin-1-yl)oxy)propanoic acid, A3

White powder, yield: $35 \%$.

${ }^{1} \mathrm{H} \mathrm{NMR}\left(400 \mathrm{MHz}, \mathrm{CDCl}_{3}\right): \delta(\mathrm{ppm})=1.71\left(\mathrm{~s}, 6 \mathrm{H}, \mathrm{CH}_{2}\right)$, $1.64\left(\mathrm{~s}, 6 \mathrm{H}, \mathrm{CH}_{3}\right), 1.33\left(\mathrm{~s}, 6 \mathrm{H}, \mathrm{CH}_{3}\right), 1.27\left(\mathrm{~s}, 6 \mathrm{H}, \mathrm{CH}_{3}\right)$, (Fig. $\mathrm{S} 3 \dagger$ ).

${ }^{13} \mathrm{C} \mathrm{NMR}\left(\mathrm{CDCl}_{3}\right): \delta(\mathrm{ppm})=176.92,82.34,62.95,39.69$, 31.17, 28.37, 20.73, 16.22, (Fig. $\mathrm{S} 4 \dagger$ ).

ESI-HRMS. Calc. for $\left[\mathrm{C}_{13} \mathrm{H}_{25} \mathrm{NO}_{3}+\mathrm{H}\right]^{+}: \mathrm{m} / z$ 244.1907, found: $m / z 244.1907$.

\section{Cationic polymerization procedure}

All cationic polymerizations were carried out under an argon atmosphere at $20{ }^{\circ} \mathrm{C}$ in a dry round bottom flask. The alkoxyamine was first added into the flask and dried under vacuum $\left(10^{-7}\right.$ bar) for 60 minutes at room temperature. Solvent, IBVE and dioxane were then added into the flask using dry syringes under an argon atmosphere. The solution was cooled to $20^{\circ} \mathrm{C}$ and the polymerization was initiated by addition of $1 \mathrm{M} \mathrm{SnBr}_{4}$ solution under an argon atmosphere. After the desired time, aliquots were removed and rapidly cooled off below $-40{ }^{\circ} \mathrm{C}$. The reaction was quenched with cooled methanol containing a small amount of aqueous ammonia solution (0.1\%). Monomer conversion was determined by ${ }^{1} \mathrm{H}$ NMR directly from aliquot solutions. For SEC analysis, polymers were purified by dilution of aliquots with DCM, washed successively with $0.1 \mathrm{M} \mathrm{HCl}$ solution, $0.1 \mathrm{M} \mathrm{NaOH}$ solution and water. The organic layer was dried over $\mathrm{MgSO}_{4}$, filtered, evaporated and polymer was dried under vacuum.

\section{Nitroxide-mediated polymerization procedure}

Typically, styrene and PIBVE-based macroalkoxyamine were dissolved in ethylbenzene $(60 \% \mathrm{v} / \mathrm{v})$. The mixture was then loaded in a three-neck flask equipped with a reflux condenser and a magnetic stir bar, purged with argon for $20 \mathrm{~min}$ at room temperature to remove oxygen. Polymerization was performed at $130{ }^{\circ} \mathrm{C}$ under an argon atmosphere. After desired times, aliquots were removed and rapidly quenched by freezing the reaction mixture in a liquid nitrogen bath. Portions of these aliquots were directly analyzed by ${ }^{1} \mathrm{H}$ NMR for determination of monomer conversion or dried over vacuum for SEC analysis.

\section{Results and discussion}

\section{Synthesis of carboxylic acid-based alkoxyamines}

Alkoxyamines were mainly prepared through two strategies, via nucleophilic substitution or via coupling reaction between an alkyl bromide and a nitroxide radical according to the Atom Transfer Radical Addition (ATRA) process. ${ }^{46,47}$ Herein, carboxylic acid-based alkoxyamines A2 and A3 have been prepared via coupling reaction (Scheme 2). Halogen transfer between $\mathrm{Cu}(\mathrm{I})$ complexes and organic halides generates the alkyl radicals which are rapidly trapped by TEMPO radicals to afford the corresponding alkoxyamines. The chemical structure of 


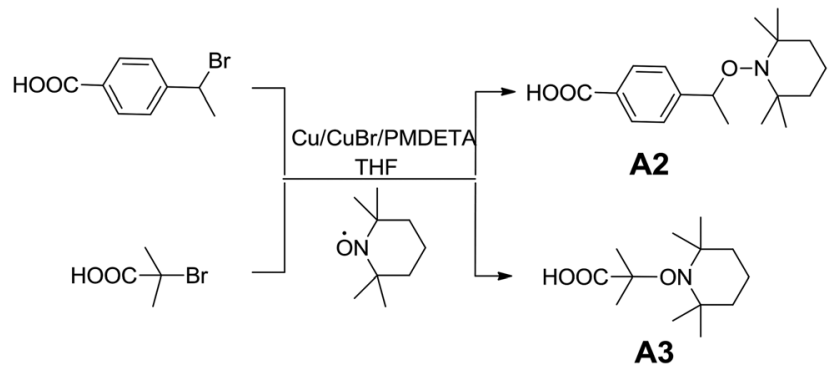

Scheme 2 Synthesis of carboxylic acid-based alkoxyamines by ATRA.

the alkoxyamines was confirmed by ${ }^{1} \mathrm{H},{ }^{13} \mathrm{C}$ NMR and HR-MS (ESI S1-4†).

Effect of alkoxyamine structure on the cationic polymerization

Previous studies in the literature showed a high efficiency of the carboxylic acid/ $\mathrm{SnBr}_{4} /$ additive-based initiation system toward the cationic polymerization of vinyl ether monomers. ${ }^{11,32,48}$ Herein, we used similar conditions to assess the cationic polymerization of IBVE using carboxylic acid-based akoxyamines as the initiator. All polymerizations of IBVE were carried out at $20{ }^{\circ} \mathrm{C}$ in the presence of dioxane, a weak base and $\mathrm{SnBr}_{4}$, a Lewis acid. The roles of dioxane are now well known to stabilize the growing carbocations, to adjust the acidity of (free) Lewis acids and to form monomeric Lewis acids. ${ }^{49-51}$ Consequently, the addition of weak bases allows to get a better polymerization control. Table 1 summarizes the results for various polymerizations carried out under different conditions. In the case of $\mathbf{A 1}$, a first test was performed with 0.1 equivalent of Lewis acid with respect to the amount of carboxylic acid-based alkoxyamine; however, no polymerization occurred (entry 1, Table 1). A higher amount of Lewis acid (0.3 eq.) was then used for the polymerization, but it also failed to produce a polymer (entry 2, Table 1). Doubling the amount of $\mathrm{SnBr}_{4}$, i.e. 0.6 eq., allowed the polymerization to occur with a relatively acceptable dispersity (1.46) (entry 3, Table 1). However, after quenching the polymerization with methanol at low temperature $\left(<-40{ }^{\circ} \mathrm{C}\right)$, the dormant polymer with termi- nated-nitroxide was not obtained. Instead, all polymer chains were terminated by a methoxy group. In similar experiments, polymerization of IBVE using $\mathrm{RCOOH}$ with $\mathrm{R}=\mathrm{CH}_{3}, \mathrm{CH}_{3} \mathrm{CH}_{2}$, $\left(\mathrm{CH}_{3}\right)_{2} \mathrm{CH}, \mathrm{C}_{6} \mathrm{H}_{5} \mathrm{CH}_{2}$ or $\left(\mathrm{C}_{6} \mathrm{H}_{5}\right)_{2} \mathrm{CH}$ led to the formation of living polymers with low dispersities (1.1-1.2) and high esterterminated functionality in the presence of only 0.1 eq. of $\mathrm{SnBr}_{4}$ as Lewis acid. ${ }^{11-13}$ Such behaviour of $\mathbf{A 1}$ is probably related to the presence of diethyl phosphate groups on the nitroxide moiety which enhances the interactions with Lewis acid $^{10}$ decreasing the catalytic efficiency of the carboxylate counter-anions of the propagating species. To evidence these interactions, 0.6 eq. of $\mathrm{SnBr}_{4}$ was added to the solution of $\mathbf{A 1}$. Fig. 1B shows the ${ }^{31} \mathrm{P}$ NMR spectrum of this mixture, in which we observed several peaks shifted towards low frequency including two intense broad peaks at 25 and $22 \mathrm{ppm}$ and three sharp small peaks at 16, 15.5 and $9 \mathrm{ppm}$ respectively. The presence of these peaks is probably the result of the interactions between nitroxide moieties of $\mathbf{A 1}$ and $\mathrm{SnBr}_{4}$ and different decomposition reactions caused by $\mathrm{SnBr}_{4}$. Subsequent addition of methanol to the solution of $\mathbf{A 1}$ and $\mathrm{SnBr}_{4}$ to neutralize $\mathrm{SnBr}_{4}$ did not allow initial peaks of $\mathbf{A 1}$ to be obtained

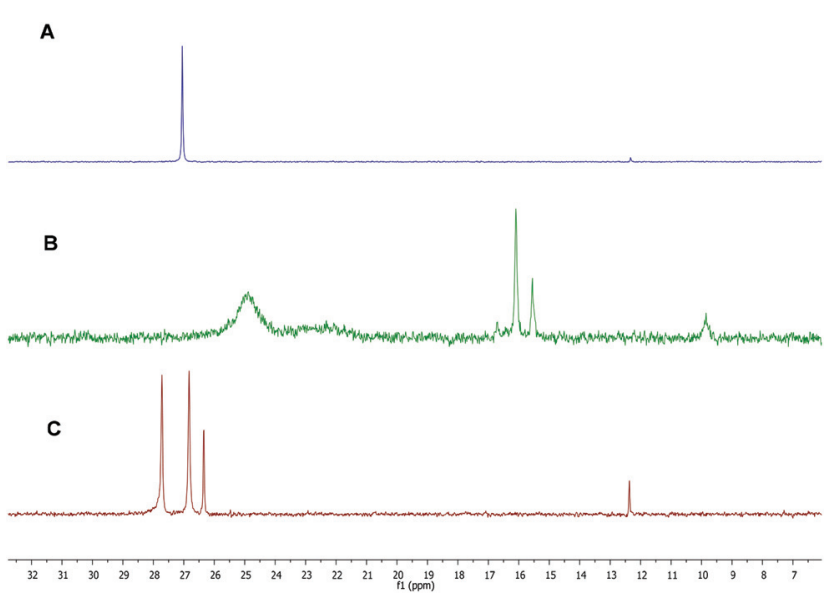

Fig. $1{ }^{31} \mathrm{P} N M R$ in $\mathrm{CDCl}_{3}$ for (A) $\mathrm{A} 1$, (B) $\mathrm{A} 1+0.6$ eq. of $\mathrm{SnBr}_{4}$ and (C) A1 +0.6 eq. of $\mathrm{SnBr}_{4}$ and quenching by $\mathrm{MeOH}$.

Table 1 Cationic polymerization of IBVE using different carboxylic acid-based alkoxyamines as initiator ${ }^{a}$

\begin{tabular}{|c|c|c|c|c|c|c|c|c|c|c|}
\hline Entry & Alkoxyamine & Solvent & $\begin{array}{l}\mathrm{SnBr}_{4} / \\
\text { A ratio }\end{array}$ & $\begin{array}{l}\text { Time } \\
\text { (h) }\end{array}$ & $\begin{array}{l}\text { Conversion } \\
(\%)\end{array}$ & $\begin{array}{l}M_{\mathrm{n}}, \text { calcd }^{b} \\
\left(\mathrm{~g} \mathrm{~mol}^{-1}\right)\end{array}$ & $\begin{array}{l}M_{\mathrm{n}, \mathrm{NMR}}{ }^{c} \\
\left(\mathrm{~g} \mathrm{~mol}^{-1}\right)\end{array}$ & 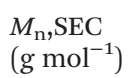 & $\begin{array}{l}\text { Dispersity } \\
(D)\end{array}$ & $F^{d}(\%)$ \\
\hline 1 & A1 & Toluene & 0.1 & 20 & - & 10384 & - & - & - & - \\
\hline 3 & & & 0.6 & 20 & $\sim 100$ & 10384 & - & 13600 & 1.46 & 0 \\
\hline 4 & A2 & Toluene & 0.1 & - & - & 10306 & - & - & - & - \\
\hline 5 & & THF & 0.1 & 24 & $\sim 100$ & 10306 & - & 6090 & 1.95 & $\sim 40$ \\
\hline 6 & A3 & Toluene & 0.1 & 0.75 & 19 & 2144 & 1844 & 3200 & 1.58 & $\sim 85$ \\
\hline
\end{tabular}

${ }^{a}$ Cationic polymerization conditions: $[\mathrm{IBVE}]_{0}=1.5 \mathrm{M},[\mathrm{A}]_{0}=0.015 \mathrm{M}$, [dioxane $]_{0}=0.14 \mathrm{M}$ in toluene at $20{ }^{\circ} \mathrm{C} .{ }^{b} M_{\mathrm{n}}$, calcd $=\mathrm{M}_{\mathrm{akoxyamine}}+\mathrm{M}_{\mathrm{IBVE}} \times$ conversion $\times\left([\mathrm{IBVE}]_{0} /[\mathrm{A}]_{0}\right)$. ${ }^{c}$ Number-average molecular weight determined by ${ }^{1} \mathrm{H}$ NMR. ${ }^{d}$ Calculated based on the peak intensity ratio of the methine proton on the hemiacetal ester to that of the methine proton on the hemiacetal ester and the methine proton produced by methanol termination. 
(Fig. 1C). This indicates that the electrophilic interactions were irreversible and/or that the alkoxyamine was decomposed in the presence of Lewis acid. ${ }^{52}$ Thus, the use of $\mathbf{A 1} / \mathrm{SnBr}_{4}$ as the initiator allowed performing the cationic polymerization of IBVE, but the produced polymer chains did not contain any nitroxyl end-group, as a consequence of low stability of $\mathbf{A 1}$ in the Lewis acid solution.

The high functionality of final polymers with a nitroxide end-group is an important factor that allows performing the next NMP step efficiently for the synthesis of block copolymers. To investigate the high end-group functionality of polymers, the cationic polymerization has been examined using TEMPO-based alkoxyamines as initiators. First, A2 with an aromatic substituent of a carboxylic group has been employed for the LCP of IBVE. In toluene, the polymerization could not be performed because of the precipitation of the initiator after addition of Lewis acid (entry 4, Table 1). Then a more polar solvent, THF, was used. The precipitation was no longer observed, but the polymerization did not occur under the truly living/controlled conditions as indicated by the broad dispersity (1.9) and low chain-end functionality (40\%, entry 5, Table 1). The non-living/controlled polymerization of a protonic acid/Lewis acid system in a polar solvent ${ }^{7}$ as well as benzoic acid/zinc chloride initiating systems $^{9}$ was also reported. The reason could be that the propagation rate was much faster than the initiation, which led to a low initiator efficiency. ${ }^{7}$ We next polymerized IBVE with alkoxyamine A3 with dimethyl substituents of carboxylic acid under the same condition as above, i.e. in toluene, 0.1 eq. of $\mathrm{SnBr}_{4}$ (entries 6-8 Table 1). The polymerization was well-controlled producing polymers with a relatively low dispersity (1.30, entry 8 , Table 1 ) without precipitation in the early period. Furthermore, the nitroxide end-chain functionality of the final polymer was high $(\sim 0.80)$. Fig. 2 shows the proton NMR of the final polymer with two kinds of terminated polymer structures, acetal and ester.
To get further evidence of nitroxide chain end functionality, a PIBVE-TEMPO with a low molar mass (entry 6, Table 1) was analyzed by ESI-MS. ESI is known as a soft ionization technique allowing mass analysis of intact polymer ions with no or little fragmentation. The ESI mass spectrum shown in Fig. 3 was obtained after dilution of the polymer sample in a methanolic solution of LiCl. Experiments conducted with alternative salts in the polymer solution (data not shown) confirmed that all species observed in Fig. 3 were lithiated molecules, all in the +1 charge state. The major distribution of singly-charged molecules (annotated with white stars) spaced by $100.1 \mathrm{~m} / \mathrm{z}$, that is, the mass of the IBVE monomeric unit, was assigned to the targeted species with $n$ ranging from 3 to 17 , as supported by accurate mass measurements (inset of Fig. 3). This assignment was further validated by MS/MS experiments, where dissociation reactions observed upon collisional activation of these lithiated oligomers provided unambiguous evidence of the $\omega$ end-group structure. Indeed, as exemplified with the case of the $\mathrm{m} / \mathrm{z} 650.6$ ion in Fig. $\mathrm{S} 5, \dagger$ the main dissociation reaction consisted of the release of TEMPO as a radical (156 $\mathrm{Da})$, followed by the elimination of the HOOC- $\left(\mathrm{CH}_{3}\right)_{2} \mathrm{C}^{\cdot}$ radical (87 Da). The $M_{\mathrm{n}}$ and $M_{\mathrm{w}}$ values of the obtained product was calculated from data of the ESI mass spectrum, using the peak intensity as $N_{\mathrm{i}}$ in the equations $M_{\mathrm{n}}=\left(\sum N_{\mathrm{i}} M_{\mathrm{i}}\right) /\left(\sum N_{\mathrm{i}}\right)$ and $M_{\mathrm{w}}=$ $\left(\sum N_{\mathrm{i}} M_{\mathrm{i}}^{2}\right) /\left(\sum N_{\mathrm{i}} M_{\mathrm{i}}\right)$, where $N_{\mathrm{i}}$ is the number of chains with mass $M_{\mathrm{i}}$. The so-obtained $M_{\mathrm{n}}$ and $M_{\mathrm{w}}$ values were $781 \mathrm{~g} \mathrm{~mol}^{-1}$ and $852 \mathrm{~g} \mathrm{~mol}^{-1}$, respectively, far below the data obtained by NMR and SEC but consistent with low mass-to-charge ions dominating the mass spectrum, as usually observed in ESI-MS.

Three other minor PIBVE series were also observed in Fig. 3. Signals designated by black diamonds were found to be non-covalent complexes generated in the ESI source between the abundant PIBVE-macroalkoxyamine and either A3 or the 1-mer of the main polymer, as revealed by MS/MS data (Fig. S6†). As a result, this peak series did not correspond to a
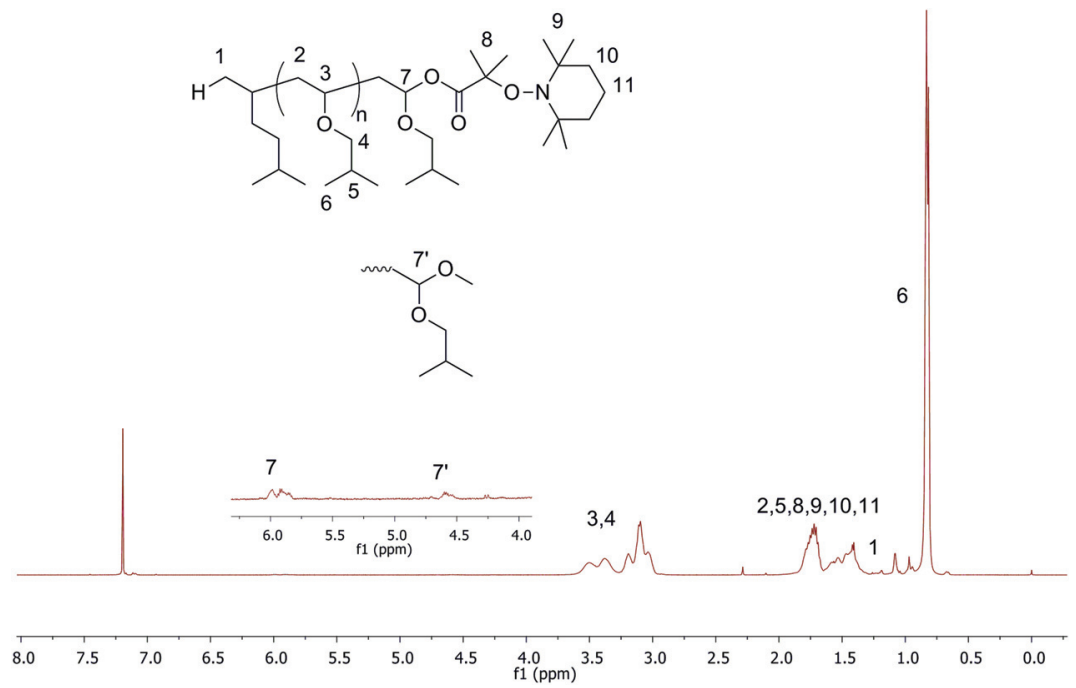

Fig. $2{ }^{1} \mathrm{H}$ NMR in $\mathrm{CDCl}_{3}$ of PIBVE synthesized using $\mathrm{A} 3$ as the initiator. The inset shows the estimated chemical structure of the PIBVE-macroalkoxyamine with full peak assignments. 

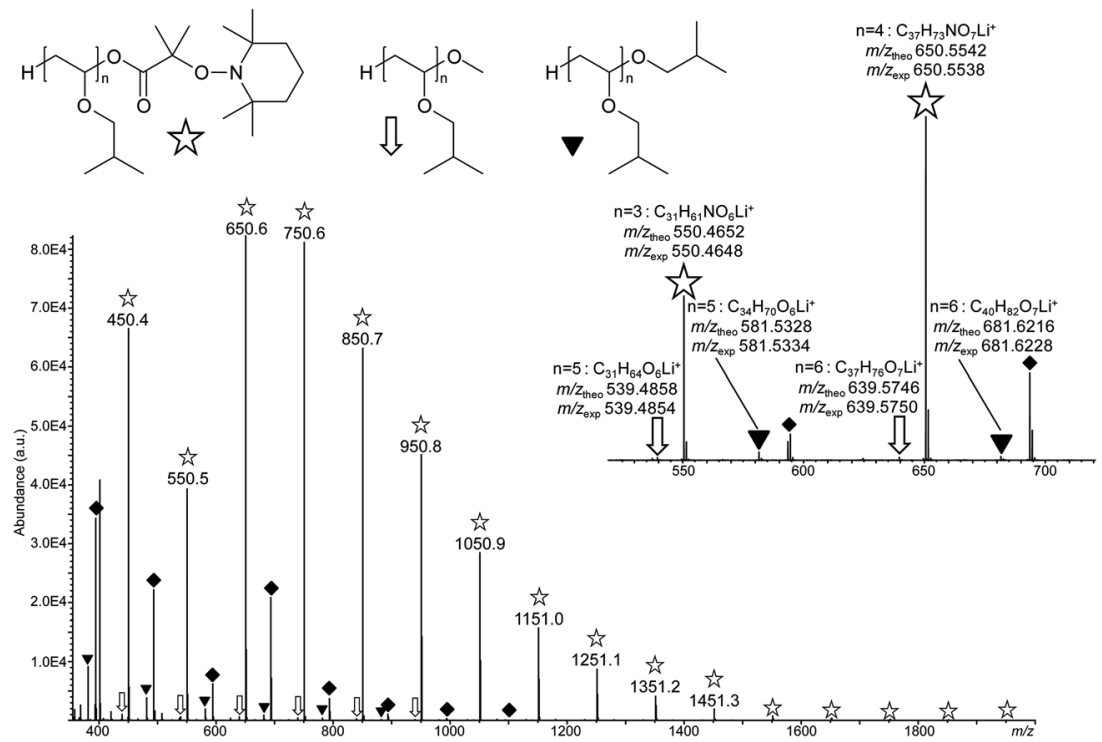

Fig. 3 ESI-MS spectrum of PIBVE-macroalkoxyamine (Table 1, entry 6), showing a major distribution of the targeted oligomers (designated with a white star), together with two minor polymer species, respectively annotated with a white arrow and a black triangle, all detected as lithiated molecules. The peak series annotated with a black diamond corresponds to non-covalent complexes formed between the PIBVE-macroalkoxyamine and residual A3. Inset: details of the mass spectrum in the $\mathrm{m} / \mathrm{z}$ 520-620 range, with elemental composition of the ions as determined from their accurately measured $\mathrm{m} / \mathrm{z}$ values $\left(\mathrm{m} / \mathrm{z}_{\text {exp }}\right)$ and structure proposed for the three observed PIBVE polymers.

new PIBVE polymer. In contrast, ions designated with white arrows were found to be lithium adducts of PIBVE polymeric impurities holding a methoxy $\omega$ end-group. This assignment was supported by accurate mass data with errors below $2 \mathrm{ppm}$ (inset of Fig. 3), as well as by the loss of a methanol molecule as a diagnostic MS/MS reaction experienced by precursor ions containing a methoxy moiety (Fig. S7†). The presence of this impurity in the PIBVE-TEMPO sample could be explained by the use of methanol as a quenching agent at the end of the polymerization. Finally, a structure was also proposed for the second minor polymeric by-products (annotated with black triangles in Fig. 3). In this PIBVE polymer, the $\omega$ end-group would have the same structure as the pendant moiety (-OiBu) of the monomeric unit, as suggested by accurate mass measurements (inset of Fig. 3) and MS/MS data (Fig. S8 †). This structure was generated by quenching with isobutanol and has already been evidenced by other authors. ${ }^{53,54}$ Obviously, the presence of isobutanol was not expected in the initial polymerization solution; its formation was most probably generated via the decomposition of an unstable hemiacetal (IVBE$\mathrm{H}_{2} \mathrm{O}$ ) formed by addition of a double bond of IBVE with $\mathrm{H}_{2} \mathrm{O}$ (Fig. S9†). ${ }^{53-56}$

In order to get more information about the control character of this polymerization, a kinetic study of IBVE cationic polymerization using $\mathbf{A} \mathbf{3}$ as the initiator was performed with a molar ratio of $[\mathrm{IBVE}] /[\mathrm{A} 3]=245 / 1$. During the polymerization, the $\ln \left([\mathrm{M}]_{\mathrm{o}} /[\mathrm{M}]_{\mathrm{t}}\right.$ ) versus time plot (Fig. $\left.4 \mathrm{~A}\right)$ clearly showed linearity with monomer conversion indicating a constant concen-
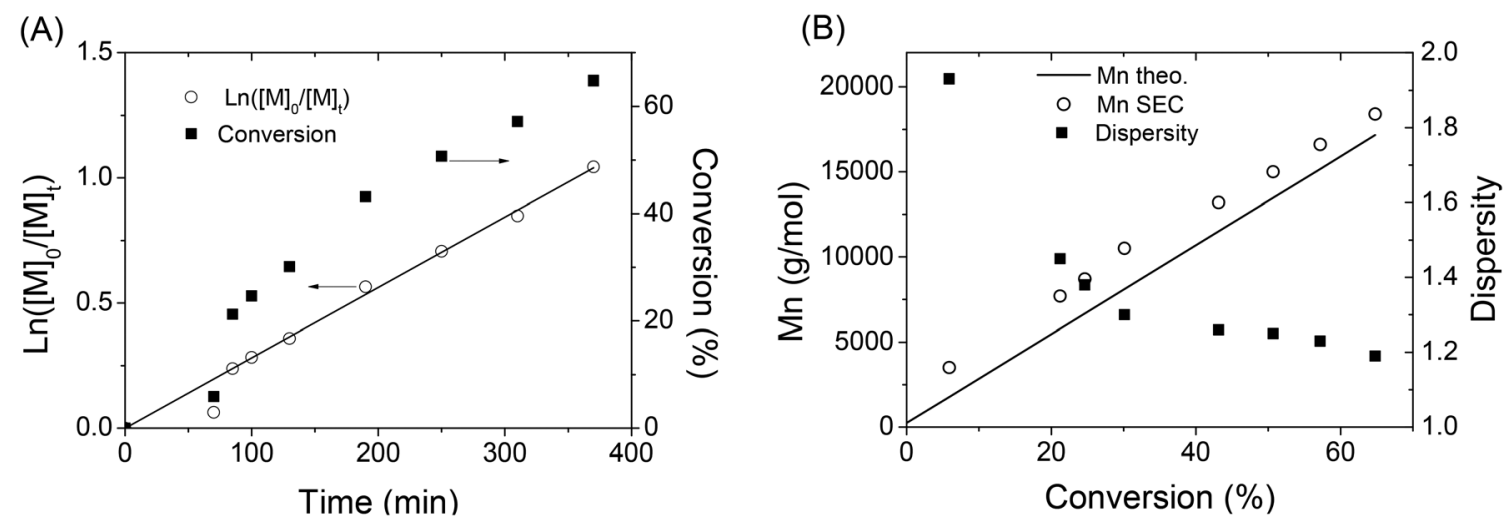

Fig. 4 (A) First-order kinetic plot and (B) evolution of molecular weight and dispersity of polymer with conversion during the CLP of IBVE using alkoxyamine $A 3$ as the dual initiator. 
tration of propagating species. Fig. 4B shows the evolution of $M_{\mathrm{n}, \mathrm{SEC}}$ and dispersity during the polymerization. Molecular weight, $M_{\mathrm{n}}$, SEC , determined by SEC in THF with an RI detector, increased linearly with conversion. The $M_{\mathrm{n}}$,SEC values are somewhat slightly higher than those predicted by the theory. It is noted that the dispersities of polymers were broad in early stage of the polymerization (1.93), and then became much narrower at high conversion ( 1.2). The SEC chromatograms of polymers are shown in the ESI (Fig. S10†). All these results showed that the alkoxyamine $\mathbf{A} 3 / \mathrm{SnBr}_{4}$ initiating system led to the living/controlled cationic polymerization of vinyl ether with high functionality of the nitroxide end-group of polymer, to be further employed as a macro-alkoxyamine for NMP of styrene.

\section{Synthesis of block copolymer using PIBVE-TEMPO as macro- alkoxyamine}

Once the cationic polymerization was optimized, a TEMPOfunctionalized PIBVE (entry 7, Table 1) was used for the NMP of styrene. In order to check the livingness of the NMP, a kinetic study of the polymerization of styrene was performed in ethylbenzene at $130{ }^{\circ} \mathrm{C}$ with a molar ratio of $[\mathrm{St}] /[\mathrm{PIBVE}-$ TEMPO $]=576 / 1$. The pseudo-first-order kinetic plot remained mostly linear indicating an approximately constant radical concentration over the polymerization of St mediated by macro-alkoxyamine (Fig. 5A). For short reaction time $(<8 \mathrm{~h})$ or low monomer conversion $(<50 \%)$, we observed a linearity of molar mass with monomer conversion (Fig. 5B) and these values were very close to the calculated ones. Furthermore, the dispersity decreased with conversion to reach low values $(1.20$ at $41 \%$ conversion). However, there is small tailing in the lower molar mass region in SEC chromatograms (Fig. 6, chromatogram 2), which was due to the low-end functionality of PIBVE produced via living cationic polymerization. Indeed, TEMPO-end functionality of the PIBVE used in this polymerization was about $82 \%$ (Table 1 , entry 7 ). For longer polymerization time $(20 \mathrm{~h})$ or higher monomer conversion $(70 \%)$, the small tailing in the region of low molar mass previously observed became larger (Fig. 6, chromatogram 3). This shoulder is superimposed to the chromatogram of PIBVEmacroalkoxyamine (Fig. 6, chromatogram 1) and thus assigned to PIBVE species. The increase of PIBVE homopolymer in the polymerization mixture for a long polymeriszation time at high temperature can be explained by the cleavage of hemiacetal ester group that links PIBVE and PS blocks. The ester bond in the hemiacetal ester group is considered as weak bond and several authors have studied its thermal stability. ${ }^{57-59}$ They found the dependence of the dissociation temperature of the ester bond with the electron-donating ability of the ester substituent, in the other words, the relative stability of the resulting cation after decomposition. ${ }^{57,58}$ Endo et al. showed that the thermal stability of bulky polymer attached with three different types of alkyl hemiacetal ester side groups varied as $1^{\circ}>2^{\circ}>3^{\circ}$ with expected order of dissociation temperature of 191,166 and $140{ }^{\circ} \mathrm{C}$ respectively. ${ }^{58}$ Therefore, the increasing presence of PIBVE homopolymer during the polymerization process at $130{ }^{\circ} \mathrm{C}$ was justified. The labile character of this hemiacetal ester group could be advantageously used in stimuli-responsive systems. Aoshima et al. demonstrated a complete and rapid degradation of hemiacetal group under acidic conditions. ${ }^{21}$

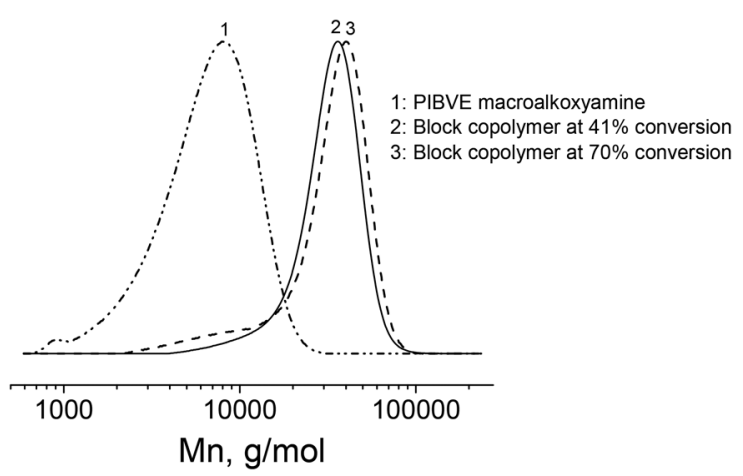

Fig. 6 SEC chromatograms of (1) PIBVE macroalkoxyamine, PS- $b$ PIBVE copolymers at (2) $41 \%$ conversion and (3) $70 \%$ conversion of St.
(A)

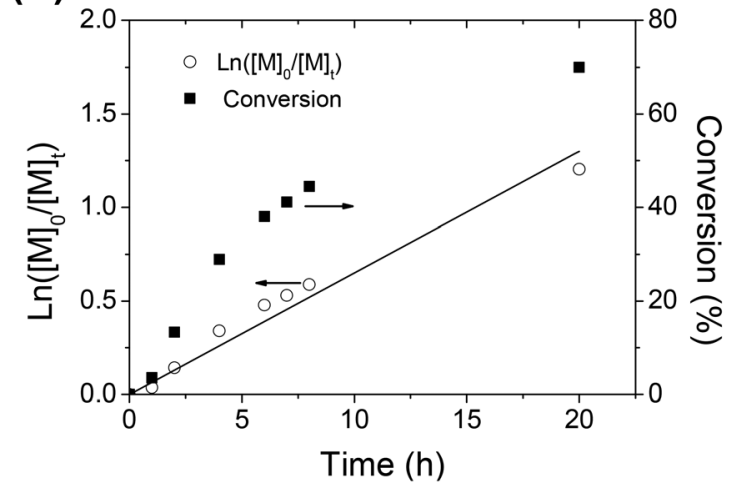

(B)

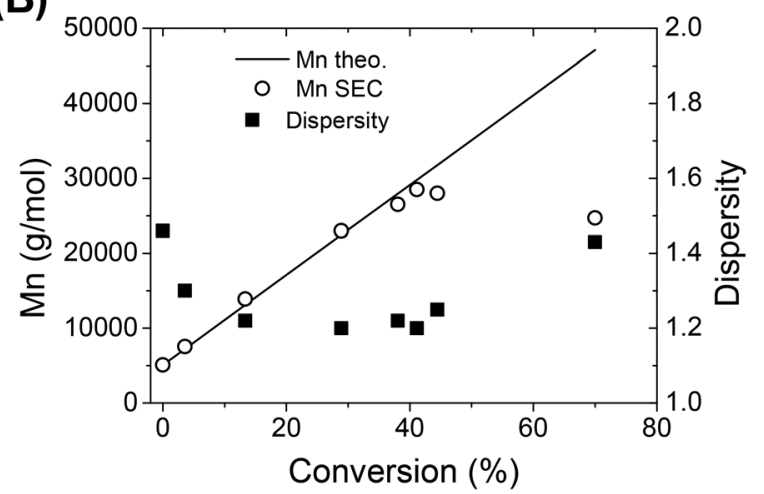

Fig. 5 (A) First-order kinetics plot and (B) evolution of molecular weight and dispersity of PIBVE- $b$-PS copolymer with conversion during the NMP of styrene using PIBVE-macroalkoxyamine as the initiator. 


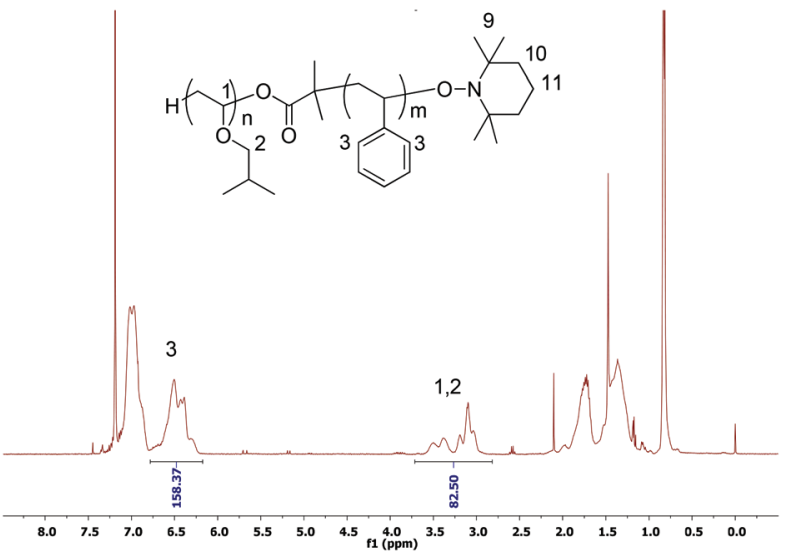

Fig. $7{ }^{1} \mathrm{H}$ NMR spectrum in $\mathrm{CDCl}_{3}$ of purified PIBVE- $b$-PS

As a typical example, the structure of the purified block copolymer at $13.3 \%$ conversion was determined by ${ }^{1} \mathrm{H}$ NMR spectroscopy as shown in Fig. 7. The copolymer was first purified by precipitation in cool ethanol to eliminate all PIBVE homopolymers. The composition of block copolymer determined by NMR, i.e. St/IBVE $=78 / 27.5$, was in good agreement with the monomer feed ratio of St to PIBVE at this conversion, which was calculated by comparing the characteristic peak intensities of the methylene and methine protons of PIBVE and of aromatic proton of PS. This result reinforces that almost PIBVE macroalkoxyamine mediated the polymerization of St to obtain block copolymer.

\section{Conclusion}

Several carboxylic acid-functionalized alkoxyamines were successfully synthesized by atom transfer radical addition reaction and used as a dual initiator for the preparation of block copolymers composed of PIBVE and PS via the combination of living cationic polymerization and nitroxide-mediated polymerization routes. The results showed that the structure of the dual initiator has a strong influence on the living/controlled characters of LCP. We demonstrated that the key to succeed cationic polymerization was the use of a suitable alkoxyamine, which has high solubility in an apolar solvent, and the latter should not cause interactions between a nitroxide moiety and Lewis acid. After the cationic polymerization of IBVE, the polymerization was quenched and the alkoxyamine group as a counteranion was concurrently recovered with high yield. The chain extension of the TEMPO-terminated PIBVE by NMP of styrene led to a well-defined diblock copolymer. Although both IBVE and styrene can be polymerized by using LCP techniques as well as the preparation of their block copolymers by sequential monomer addition have been reported, ${ }^{60}$ we are confident that the use of a carboxylic-based alkoxyamine as a dual initiator can be applied in the synthesis of block copolymers with a well-defined structure, which cannot be polymerized by using the LCP method such as styrene derivatives (sodium 4-vinylbenzenesulfonate, 4-nitrostyrene or 4-aminostyrene, etc.).

\section{Acknowledgements}

This work was financially supported by Aix-Marseille University and CNRS.

\section{References}

1 F. H. Schacher, P. A. Rupar and I. Manners, Angew. Chem., Int. Ed., 2012, 51, 7898.

2 N. Hadjichristidis, S. Pispas and G. Floudas, Block copolymers: synthetic strategies, physical properties, and applications, John Wiley \& Sons, 2003.

3 Y. Yagci and M. A. Tasdelen, Prog. Polym. Sci., 2006, 31, 1133.

4 K. V. Bernaerts and F. Du Prez, Prog. Polym. Sci., 2006, 31, 671.

5 C. J. Hawker, J. L. Hedrick, E. E. Malmström, M. Trollsås, D. Mecerreyes, G. Moineau, P. Dubois and R. Jérôme, Macromolecules, 1998, 31, 213.

6 T. Higashimura, M. Miyamoto and M. Sawamoto, Macromolecules, 1985, 18, 611.

7 H. Bouchekif, A. Sulhami, R. Alghamdi, Y. Gnanou and N. Hadjichristidis, Polym. Chem., 2015, 6, 1236.

8 M. Sawamoto, Prog. Polym. Sci., 1991, 16, 111.

9 M. Kamigaito, K. Yamaoka, M. Sawamoto and T. Higashimura, Macromolecules, 1992, 25, 6400.

10 M. Kamigaito, M. Sawamoto and T. Higashimura, J. Polym. Sci., Part A: Polym. Chem., 1993, 31, 2987.

11 T. Hashimoto, T. Iwata, N. Uchiyama and T. Kodaira, J. Polym. Sci., Part A: Polym. Chem., 1999, 37, 2923.

12 T. Hashimoto, T. Iwata, A. Minami and T. Kodaira, J. Polym. Sci., Part A: Polym. Chem., 1998, 36, 3173.

13 T. Hashimoto, T. Takahashi and T. Kodaira, J. Polym. Sci., Part A: Polym. Chem., 2000, 38, 781.

14 M. Minoda, M. Sawamoto and T. Higashimura, Macromolecules, 1987, 20, 2045.

15 S. Zhou, Y. Oda, A. Shimojima, T. Okubo, S. Aoshima and A. Sugawara-Narutaki, Polym. J., 2015, 47, 128.

16 S. Sugihara, S. Kanaoka and S. Aoshima, J. Polym. Sci., Part A: Polym. Chem., 2004, 42, 2601.

17 Y. Oda, S. Kanaoka, T. Sato, S. Aoshima and K. Kuroda, Biomacromolecules, 2011, 12, 3581.

18 S. Sugihara, K. Hashimoto, S. Okabe, M. Shibayama, S. Kanaoka and S. Aoshima, Macromolecules, 2004, 37, 336.

19 S. Sugihara, S. Kanaoka and S. Aoshima, Macromolecules, 2005, 38, 1919.

20 S. Sugihara, S. Ito, S. Irie and I. Ikeda, Macromolecules, 2010, 43, 1753.

21 S. Aoshima, Y. Oda, S. Matsumoto, Y. Shinke, A. Kanazawa and S. Kanaoka, ACS Macro Lett., 2013, 3, 80. 
22 J. Pretula, K. Kaluzynski, B. Wisniewski, R. Szymanski, T. Loontjens and S. Penczek, J. Polym. Sci., Part A: Polym. Chem., 2008, 46, 830.

23 T. Hashimoto, T. Imaeda, S. Irie, M. Urushisaki and T. Sakaguchi, J. Polym. Sci., Part A: Polym. Chem., 2015, 53, 1114.

24 T. Namikoshi, T. Hashimoto, Y. Makino, T. Imaeda, M. Urushisaki and T. Sakaguchi, Polym. Bull., 2014, 71, 1389.

25 E. Mishima, T. Yamada, H. Watanabe and S. Yamago, Chem. - Asian J., 2011, 6, 445.

26 E. Mishima and S. Yamago, Macromol. Rapid Commun., 2011, 32, 893.

27 A. H. Ma'Radzi, S. Sugihara, S. Miura, N. Konegawa and Y. Maeda, Polymer, 2014, 55, 1920.

28 K. Yamada, M. Miyazaki, K. Ohno, T. Fukuda and M. Minoda, Macromolecules, 1999, 32, 290.

29 O. Nuyken, H. Kröner and S. Aechtner, Makromol. Chem., Rapid Commun., 1988, 9, 671.

30 J. Lu, H. Liang, A. Li and Q. Cheng, Eur. Polym. J., 2004, 40, 397.

31 S. Sugihara, K. Yamashita, K. Matsuzuka, I. Ikeda and Y. Maeda, Macromolecules, 2011, 45, 794.

32 S. Sugihara, K. Iwata, S. Miura, A. H. Ma'Radzi and Y. Maeda, Polymer, 2013, 54, 1043.

33 S. Sugihara, N. Konegawa and Y. Maeda, Macromolecules, 2015, 48, 5120.

34 H. Aoshima, M. Uchiyama, K. Satoh and M. Kamigaito, Angew. Chem., Int. Ed., 2014, 53, 10830.

35 M. Uchiyama, K. Satoh and M. Kamigaito, Angew. Chem., Int. Ed., 2015, 54, 1924.

36 K. V. Bernaerts and F. E. Du Prez, Polymer, 2005, 46, 8469.

37 M. Ouchi, A. Konishi, M. Takenaka and M. Sawamoto, Polym. Chem., 2012, 3, 2193.

38 S. Kumagai, K. Nagai, K. Satoh and M. Kamigaito, Macromolecules, 2010, 43, 7523.

39 J. Nicolas, Y. Guillaneuf, C. Lefay, D. Bertin, D. Gigmes and B. Charleux, Prog. Polym. Sci., 2013, 38, 63.

40 J.-L. Couturier, O. Guerret, D. Bertin, D. Gigmes, S. Marque, P. Tordo, F. Chauvin and P. E. Dufils, WO 2004/ 014926, 2004.
41 X. Zhang and K. Matyjaszewski, Macromolecules, 1999, 32, 7349.

42 J. T. Lai, D. Filla and R. Shea, Macromolecules, 2002, 35, 6754.

43 Y. Kishimoto, S. Aoshima and T. Higashimura, Macromolecules, 1989, 22, 3877.

44 B. Charleux, J. Nicolas and O. Guerret, Macromolecules, 2005, 38, 5485 .

45 J. Nicolas, S. Brusseau and B. Charleux, J. Polym. Sci., Part A: Polym. Chem., 2010, 48, 34.

46 K. Matyjaszewski, Macromol. Symp., 1996, 111, 47.

47 K. Matyjaszewski, B. E. Woodworth, X. Zhang, S. Gaynor and Z. Metzner, Macromolecules, 1998, 31, 5955.

48 H. Ito and D. C. Miller, J. Polym. Sci., Part A: Polym. Chem., 2004, 42, 1468.

49 A. Kanazawa, Y. Hirabaru, S. Kanaoka and S. Aoshima, J. Polym. Sci., Part A: Polym. Chem., 2006, 44, 5795.

50 S. Aoshima, T. Yoshida, A. Kanazawa and S. Kanaoka, J. Polym. Sci., Part A: Polym. Chem., 2007, 45, 1801.

51 S. Aoshima and T. Higashimura, Macromolecules, 1989, 22, 1009.

52 N. Chagneux, T. Trimaille, M. Rollet, E. Beaudoin, P. Gerard, D. Bertin and D. Gigmes, Macromolecules, 2009, 42, 9435.

53 H. Katayama, M. Kamigaito and M. Sawamoto, J. Polym. Sci., Part A: Polym. Chem., 2001, 39, 1249.

54 A. Kanazawa, S. Kanaoka and S. Aoshima, J. Polym. Sci., Part A: Polym. Chem., 2010, 48, 3702.

55 Q. Huang, Y. Wu and J. Dan, J. Polym. Sci., Part A: Polym. Chem., 2013, 51, 546.

56 A. V. Radchenko, S. V. Kostjuk and F. Ganachaud, Polym. Chem., 2013, 4, 1883.

57 H. Otsuka and T. Endo, Macromolecules, 1999, 32, 9059.

58 B. Barkakaty, K. Matsumoto and T. Endo, Macromolecules, 2009, 42, 9481.

59 M. Shirai, K. Mitsukura and H. Okamura, Chem. Mater., 2008, 20, 1971.

60 T. Ohmura, M. Sawamoto and T. Higashimura, Macromolecules, 1994, 27, 3714. 